\title{
Beckman Coulter, Inc
}

National Cancer Institute

\section{Source}

National Cancer Institute. Beckman Coulter, Inc. NCI Thesaurus. Code C113706.

A manufacturer of biomedical laboratory instruments. 